\title{
Der Befreiungsschlag
}

\section{Erhard Taverna}

Dr. med., Mitglied der Redaktion

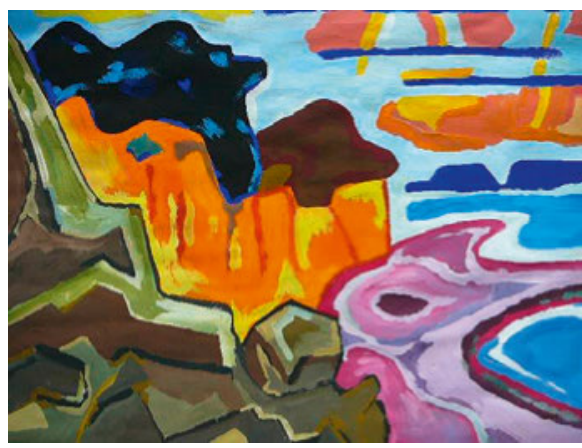

Ärger in der Praxis, mit der Familie, mit der Freundin, mit dem Steueramt, Verluste an der Börse, eine neue Qualitätsprüfung? Lassen Sie sich etwas Ausserordentliches schenken oder, noch besser, wagen Sie etwas Mutiges im neuen Jahr. Gründen Sie einen Kleinstaat. Nicht virtuell im Kopf, das kann jeder. Nein, ganz real, territorial.

Vielleicht denken Sie jetzt an Schrebergärtner, die auf ihren paar Quadratmetern einen hohen Mast pflanzen, mit einer eigenen Fahne ganz weit oben. Viel zu kleinkariert, es gibt Besseres. Machen Sie es wie der Industrielle in Müllheim, Kanton Thurgau. Aus Ärger über unsere Sozialbürokratie, die unsere Einwohner verwöhnt, hat der Unternehmer eine Gegenwelt geschaffen. Einen Mikrostaat namens Avalon, was Apfelgarten bedeutet und deshalb gut zu Mostindien passt. Ein stattlicher Regierungssitz und eine eigene Währung gehören nun mal dazu. In diesem Fall Silber- und Goldmünzen mit dem eigenen Konterfei. Zugegeben, das kostet Geld, das Ihnen möglicherweise vorübergehend fehlt. Natürlich hat Avalon keinen Sitz in der UNO-Vollversammlung und wird völkerrechtlich nicht als Staat anerkannt. Doch das tut nichts zur Sache, es geht um das eigene Ego, um Ihre Seelenmassage im neuen Jahr. Die Selbstinszenierung ist nicht neu. Es soll über vierhundert dieser Kleingebilde geben, die im Unterschied zu Monaco, dem Vatikan oder Lichtenstein offiziell nicht anerkannt sind, aber untereinander Kontakt haben. Trotz globalem Dichtestress gibt es immer noch unbewohnte Inseln, verlassene Ölplattformen, irgendein Niemandsland oder stabile Eisberge, die auf einen Besitzer warten. Einige Pazifikinseln mit schönen Namen wie Taongi, Malpelo und Solkope sind seit langem Geschäftssitz lukrativer Offshore-Banken. Das Fürstentum Sealand, eine verlassene Seefestung ausserhalb der Hoheitsgewässer, ist seit fünfzig Jahren im Familienbesitz, und ein Königreich Redonda existiert seit 1880 in der Karibik. Es gibt sogar ein Königinnenreich der dominanten Frauen, regiert von Königin Patricia I. Besuchervisa für Männer sind dort hundert Mal teurer als für Frauen. Es kann natürlich vorkommen, dass ein anerkannter Staat etwas dagegen hat, wie Tonga, das gegen ein Millionärsprojekt auf einem Pazifik-Atoll militärisch intervenierte. Das soll aber niemanden abschrecken, denn in der Regel handeln die meisten Regierungen verständnisvoll und zurückhaltend, solange die neuernannten Reiche den Verkehr nicht behindern und Steuern bezahlen. Die herrschende Aristokratie ist von hohem Rang und gut vernetzt. Ein Grossherzog von Flandrensis in der Antarktis besucht den Fürst vom Hutt River in Australien, der mit der Prinzessin Emily vom Königreich Nordsudan twittert. Viele leben vom Tourismus und sind in Promimagazinen gerngesehene Gäste. Sie tragen Generalsuniformen, Hermelinpelze, Ordensbänder und schicke Klamotten, lassen eigene Pässe herstellen und eigenes Geld prägen. Der Adel überwiegt. Selten gehören Hippie-Kommunen zu den Gründern, zum Beispiel einer Freistadt Christiana auf einem verlassenen Militärgelände in Kopenhagen. Künstler gehen auch mit gutem Beispiel voran, etwa als Gründer von Ladonien in Schweden oder der Republik Kugelmugel im Wiener Prater. Wer Erfolg hat, hat auch eine Flagge und lässt sich durch einen Honorarkonsul vertreten. Rühmenswertes Beispiel ist das Antike Fürstentum Seborga in Italien, dessen sechshundert Einwohner der Floristikunternehmer Fürst Georg I. milde regiert. Besucher können dort ihren schwächelnden Euro gegen einen Luigino eintauschen.

Zugegeben, es wird eng auf dieser Erde. Da gehen zum Glück innovative Pioniere ans Werk. Da gibt es ein käufliches Bürgerrecht im Fürstentum Lichtenberg auf dem Mond, und die Lunar Embassy eines amerikanischen Geschäftsmannes handelt Grundstücke auf diversen Planeten und Monden unseres Sonnensystems. Zwar gibt es seit 1967 einen Outer Space Treaty der vereinten Nationen, der die Inbesitznahme von extraterrestrischem Gelände verbietet. Dabei gingen allerdings Individuen und private Firmen vergessen. Gemäss internationalem Recht braucht es für einen Staat nur eine Population und ein Territorium. Anerkennung ist Nebensache. Bereits wurde kürzlich in Paris die Gründung des ersten Nationalstaates im Weltall angesagt. Für sein Asgardia sucht ein russischer Oligarch noch interessierte Bürgerinnen und Bürger.

Luftschlösser werden real. Es wird Zeit für einen mutigen Schritt. Werden Sie König Viertelvorzwölf in Lummerland. Ich wünsche Ihnen viel Glück dabei.

Bildnachweis

Erhard Taverna 